Chapman University

Chapman University Digital Commons

Pharmacy Faculty Articles and Research

School of Pharmacy

2014

\title{
Implementation of a Pharmacy-Based Adult Vaccine Benefit: Recommendations for a Commercial Health Plan Benefit
}

Jeffery A. Goad

Chapman University,goad@chapman.edu

Kelly J. Ko

Cerner Corporation

Rolin L. Wade

IMS Health

Hsing-Ting Yu

Cerner Corporation

Ross M. Miller

Cerner Corporation

See next page for additional authors

Follow this and additional works at: http://digitalcommons.chapman.edu/pharmacy_articles

Part of the Diseases Commons, Health and Medical Administration Commons, and the Pharmacy Administration, Policy and Regulation Commons

\section{Recommended Citation}

Ko, K. J., Wade, R. L., Yu, H. T., Miller, R. M., Sherman, B., \& Goad, J. Implementation of a Pharmacy-Based Adult Vaccine Benefit: Recommendations for a Commercial Health Plan Benefit. J Manag Care Pharm. 2014; 20(3): 273-82.

This Article is brought to you for free and open access by the School of Pharmacy at Chapman University Digital Commons. It has been accepted for inclusion in Pharmacy Faculty Articles and Research by an authorized administrator of Chapman University Digital Commons. For more information,

please contact laughtin@chapman.edu. 


\section{Implementation of a Pharmacy-Based Adult Vaccine Benefit: Recommendations for a Commercial Health Plan Benefit}

\section{Comments}

This article was originally published in Journal of Managed Care Pharmacy, volume 20, issue 3, in 2014.

\section{Copyright}

Academy of Managed Care Pharmacy

\section{Authors}

Jeffery A. Goad, Kelly J. Ko, Rolin L. Wade, Hsing-Ting Yu, Ross M. Miller, and Bruce Sherman 


\title{
Implementation of a Pharmacy-Based Adult Vaccine Benefit: Recommendations for a Commercial Health Plan Benefit
}

\author{
Kelly J. Ko, PhD; Rolin L. Wade, RPh, MS; Hsing-Ting Yu, MPH; Ross M. Miller, MD, MPH; \\ Bruce Sherman, MD; and Jeff Goad, PharmD, MPH
}

\begin{abstract}
BACKGROUND: Although vaccination rates in children exceed $90 \%$ in the United States, adults are vaccinated at far lower rates. In order to address this issue, additional community immunizers are needed, and pharmacists are in an ideal position to fill this void.

OBJECTIVES: To explore issues and barriers related to implementation of a pharmacy-based adult vaccine benefit and develop recommendations supporting a pathway for benefit expansion.

METHODS: A literature review on the current environment surrounding pharmacy-based adult vaccinations and structured interviews were conducted to inform an expert panel meeting using a modified Delphi process (pre/post survey). The goal was to develop recommendations on how to improve access to adult vaccines.

RESULTS: Findings suggest employers play a key role in requesting changes in benefit design to include pharmacy-based vaccinations. However, the lack of consistent communication between pharmacists and primary care providers remains a significant barrier.

CONCLUSIONS: Pharmacy-based access to vaccinations improves patient access and benefits individuals and employers. In order to take advantage of this opportunity, pharmacists must be viewed within the broader context of preventative care, including pharmacy-based vaccinations.
\end{abstract}

J Manag Care Pharm. 2014;20(3):273-82

Copyright $\odot 2014$, Academy of Managed Care Pharmacy. All rights reserved.

\section{What is already known about this subject}

- Although vaccination rates in children exceed 90\% in the United States, adults are vaccinated at far lower rates.

- To address this issue, additional community immunizers are needed, and pharmacists are in an ideal position to fill this void

- A pharmacy-based benefit would improve patient access and reduce the incidence of vaccine-preventable disease.

\section{What this study adds}

- Exploration of issues and barriers related to implementation of a pharmacy-based adult vaccine benefit.

- Specific recommendations supporting a pathway for health benefit expansion from a health plan, employer, and pharmacy perspective.
T he rate of adult immunization is suboptimal in the United States. In contrast with childhood vaccination rates, adult vaccination rates remain low for most Centers for Disease Control and Prevention (CDC) Advisory Committee on Immunization Practice (ACIP)-recommended vaccines. Although vaccination rates in children typically exceed $90 \%$ in the United States, ${ }^{1}$ adults continue to be vaccinated at low and variable rates. For example, data from 2011 show that only 16\% of adults had received a recommended herpes zoster vaccination to prevent shingles, and only $30 \%$ of young women aged 19-26 years in the United States had received $\geq 1$ dose of the human papilloma (HPV) vaccination, ${ }^{2}$ while among adolescent girls aged 13-17 years, only 53\% reported receiving $\geq 1$ dose, and only $35 \%$ reported $\geq 3$ doses of the HPV vaccine. ${ }^{3}$

Numerous reports in recent years have called for action to improve adult vaccination rates. Barriers noted in these studies to improving adult vaccination rates include failure of the vaccine delivery system to reach target populations, ${ }^{4,5}$ lack of public knowledge regarding risks of vaccine-preventable diseases, ${ }^{6,7}$ skepticism regarding vaccine safety and effectiveness, ${ }^{6-8}$ lack of financial/reimbursement systems for providers, ${ }^{4,6,9}$ lack of administrative systems for identifying appropriate patients in medical records and generating vaccination reminders, ${ }^{6,10}$ and the lack of vaccination-related performance measures and incentives (for payers and providers). ${ }^{11}$

In 2010, the Second National Immunization Congress was convened with the goal of addressing future vaccine financing for the United States, with additional focus on adult immunization infrastructure barriers and access challenges. ${ }^{12}$ Identifying community immunizers who can supplement the role of primary care providers (PCPs) becomes pertinent given that immunization recommendations will expand over the coming years, while primary care is already reeling under present service demands and cost containment. ${ }^{13}$ Currently, more than 170,000 pharmacists in the United States have been trained to provide immunizations, primarily through the nationally recognized certificate training program provided by the American Pharmacist Association. Pharmacists follow ACIP guidelines as recommended by the CDC and other public health entities, as required by state law. A pharmacy-based immunization benefit as used throughout this article relates to vaccines being initiated by pharmacists in community pharmacies, and vaccines would be a covered benefit as it would be in a physician's office. 
However, while the community pharmacy is in an excellent position to support national adult immunization goals, there are a limited number of commercial health plans that offer a pharmacy-based immunization benefit, and even when provided, not all ACIP-recommended adult vaccines are covered or available at the pharmacy. The objectives of this study were to explore issues and barriers related to implementation of a pharmacy-based adult vaccine benefit and develop specific recommendations supporting a pathway for health benefit expansion as the standard of care.

\section{Methods}

A literature review to investigate the current environment surrounding pharmacy-based adult vaccinations and structured interviews with professionals highly knowledgeable about pharmacy-based adult vaccinations were used to inform an expert panel meeting using a modified Delphi technique with a pre/post survey. ${ }^{14}$ Following the literature review, the structured interviews were conducted to further identify and clarify the range of barriers and issues associated with developing a pharmacy-based adult vaccine benefit. This led to a full-day expert panel meeting composed of individuals with experience and expertise in pharmacy-based adult vaccinations, with the goal of developing specific recommendations and building consensus where possible for improving access to adult vaccines through a pharmacy-based immunization benefit. This research project was approved by the University of Southern California Health Sciences Campus Institutional Review Board on November 16, 2012.

\section{Literature Review}

A comprehensive literature review was conducted to identify relevant papers in the peer-review literature (MEDLINE 2002-January 2013). In addition, a search of nonindexed sources including professional association websites such as America's Health Insurance Plans, Academy of Managed Care Pharmacy, American Pharmacists Association, health plan websites, and nonindexed publications was conducted. Search terms included "vaccine," "immunization," "pharmacy," "pharmacy benefit," "health plan," "managed care," and "cost-effectiveness." The search strategy identified more than 25 studies, articles, and other references available for evaluation. Findings from the literature review were used to develop the structured interview guide and to build content for key discussion topics for the expert panel meeting.

\section{Structured Interviews}

Following the literature review, a series of brief (20-30 minutes) structured telephone interviews were conducted with a convenience sample of 3 opinion leaders knowledgeable about pharmacy-based immunization benefits. Participants for the structured interview were selected based on their knowledge of, or association with, policy regarding adult vaccinations and pharmacy provision of such. In particular, we identified individuals representing a national pharmacy and medical organization, as well as a local health plan. Of the 3 opinion leaders, 1 was invited to participate in the expert panel meeting. The structured interview guide was used to address 9 openended questions (see Appendix A, available in online article). Participation in the structured interview was voluntary, and the discussion was conducted in a heuristic manner, allowing the interviewers to probe beyond the initial question. The results from the structured interviews were used to construct the consensus-generating pre/post meeting survey, which was used during the expert panel to help facilitate discussion.

\section{Recruitment of the Expert Panel}

Members of the expert panel were recruited based on recommendations from participants in the structured interview and a profile of leadership in the area of adult vaccines and pharmacy-based health care benefits. We targeted individuals based on their organizational (i.e., health plan, large employers) or professional (i.e., national pharmacy/medical organizations) affiliations, as well as publications in the area of adult vaccinations. The 12-member panel was composed of health plan (3) and pharmacy benefit managers (PBM; 3), medical/pharmacy directors, employer medical and health benefits directors (3), chain pharmacy representatives (2), and an immunization policy expert (1). An academic pharmacist immunization expert was employed as the key opinion leader to provide input and facilitate discussion.

\section{Modified Delphi Process}

The modified Delphi process included 2 rounds of ratings. In round 1 , leading up to the meeting, panelists were asked to complete a brief premeeting survey to rate statements pertaining to adult vaccinations (see Appendix B, available in online article). The goal of the survey was to determine baseline viewpoints of each panelist and to identify areas of consensus and disagreement among the various stakeholders. By doing so, the subsequent in-person discussion could be more focused. In round 2, at the close of the meeting, panelists were asked to complete a postmeeting survey consisting of select opinionbased questions from the premeeting survey to determine if panelists' views changed after the meeting. We utilized a modified Delphi technique as opposed to a traditional Delphi technique, since responses were not anonymous, and we used only 2 rounds of rating regardless of consensus.

The pre- and postmeeting surveys were developed based on findings from the literature review and feedback from the structured interviews. The survey was composed of 3 different sections: The first focused on general background information regarding adult vaccination and vaccination rates; the second section asked specifically about pharmacy-based adult vaccination; and the third section focused on research/resources relevant to a pharmacy-based benefit. The survey asked 
Lack of public recognition regarding need for adult vaccinations impacts adult vaccination rates

Cost of vaccines for patients impacts adult vaccination rates

Vaccine shortages impact adult vaccination rates

Physicians are responsible for helping to improve adult vaccination rates

Patients are responsible for helping to improve adult vaccination rates

Health plans are responsible for helping to improve adult vaccination rates

A pharmacy-based adult vaccination benefit would improve adult

vaccination rates

A pharmacy-based adult vaccination benefit would result in cost savings for the health plan and employer

A pharmacy-based benefit would improve public acceptance of vaccine safety/effectiveness

Ease of access for patients is important when/if considering a pharmacy-based adult vaccine benefit

Coordinated reporting of vaccines is important when/if considering a pharmacy-based adult vaccine benefit

Lack of standard reimbursement process is a significant barrier

Uncertain cost-effectiveness is a significant barrier

Safety of vaccines administered by pharmacists is an issue

${ }^{a}$ Denotes number of panelists who were in disagreement, unsure, or agreement with respective survey questions.

\begin{tabular}{|c|c|c|c|c|c|c|c}
\hline \multicolumn{2}{|c|}{$\begin{array}{c}\text { Disagreement } \\
(1-3)\end{array}$} & \multicolumn{2}{c|}{$\begin{array}{c}\text { Unsure } \\
(5-7)\end{array}$} & \multicolumn{2}{c|}{$\begin{array}{c}\text { Agreement } \\
(7-9)\end{array}$} & \multicolumn{2}{c}{ Mean } \\
\hline Prea $^{\mathrm{a}}$ & Post $^{\mathrm{a}}$ & Pre & Post & Pre & Post & Pre & Post \\
\hline 1 & 2 & 2 & 2 & 9 & 8 & 7.08 & 6.58 \\
\hline 1 & 0 & 2 & 1 & 9 & 11 & 7.25 & 7.83 \\
\hline 2 & 3 & 6 & 5 & 3 & 4 & 5.75 & 5.25 \\
\hline 4 & 4 & 2 & 4 & 6 & 4 & 5.33 & 5.42 \\
\hline 0 & 0 & 0 & 0 & 12 & 12 & 8.33 & 8.58 \\
\hline 0 & 1 & 1 & 0 & 11 & 11 & 7.92 & 7.67 \\
\hline 1 & 0 & 0 & 3 & 11 & 9 & 7.50 & 7.42 \\
\hline 1 & 0 & 0 & 1 & 11 & 11 & 7.17 & 7.50 \\
\hline 1 & 2 & 4 & 4 & 7 & 6 & 6.75 & 5.83 \\
\hline 1 & 1 & 5 & 3 & 6 & 8 & 6.00 & 6.50 \\
\hline 1 & 1 & 1 & 1 & 10 & 10 & 7.42 & 7.75 \\
\hline 0 & 0 & 3 & 0 & 9 & 12 & 7.25 & 8.33 \\
\hline 2 & 0 & 1 & 2 & 9 & 10 & 6.92 & 7.75 \\
\hline 4 & 1 & 5 & 7 & 3 & 4 & 5.08 & 5.67 \\
\hline 5 & 7 & 4 & 4 & 3 & 1 & 4.75 & 3.25 \\
\hline
\end{tabular}

panelists to provide ratings on a 9-point scale ( $1=$ strongly disagree; 5 =uncertain; $9=$ strongly agree), as well as respond to several open-ended questions. Average ratings between 1 and 3 were considered as indicating disagreement, average ratings between 4 and 6 as uncertain, and average ratings between 7 and 9 as indicating agreement. Disagreement or lack of consensus was defined as occurring when at least 2 panelists rated any scenario as disagree (1-3) and at least 2 panelists rated the same statement as agree (7-9), regardless of average rating. The survey included 3 separate sections focusing on (a) background knowledge on adult vaccinations, (b) perspective regarding pharmacy-based adult vaccination benefit, and (c) areas of need pertaining to future studies/research. In addition to rating each statement, panelists could also add comments to particular statements.

\section{Expert Panel Meeting}

The expert panel meeting was organized into four 90-minute sessions over the course of the day, with each session having a distinct focus. The goal for the first session was to have an open discussion about the current state of pharmacy-based adult vaccine benefits. Panelists were provided with an overview of findings from the literature review and encouraged to share initial thoughts based on their experience and understanding of pharmacy-based adult vaccine benefits. Round 2 of the modified Delphi model occurred during the second session. Results from the premeeting survey were used to frame discussions and target areas where there was disagreement or where consensus was lacking; panelists were asked to elaborate on their responses (see Appendix C, available in online article). The goal for the second session was to reach initial consensus on issues where survey results indicated there was disagreement. The goal of the third session was to share new information and research regarding pharmacists as vaccinators and issues related to vaccine financing currently and in the near future. During the third session, our focus was to inform panelists of information with which they may not have been familiar. The fourth session focused on producing workgroup consensus and recommendations across 6 broad areas that were previously identified through the literature review and structured interviews. The goal of the fourth session was to drive the discussion toward specific recommendations to provide a roadmap leading to a pharmacy-based adult immunization benefit design.

\section{Results}

\section{Survey}

The response rate for the pre- and postmeeting survey was $100 \%(n=12)$, and there were no missing data. Select results from both the pre- and postmeeting survey are presented in Table 1 . The premeeting survey asked panelists to rate various statements ( 1 =strongly disagree; 5 =uncertain; 9 =strongly agree) and revealed general agreement that health plan benefit 
design and lack of public recognition regarding the importance of adult vaccinations were important barriers to improving adult vaccination rates. However, panelists disagreed on the importance of the cost of vaccines and the impact of vaccine shortages on adult vaccination rates. When panelists were asked what they believed were the most significant barriers to improving adult vaccination rates, payment processing and lack of coordinated reporting were most frequently identified. When asked about who was most responsible for improving vaccination rates, they reported physicians, patients, and health plans, while there was disagreement regarding the responsibility of government regulators and government payers on improving rates. Although panelists were in general agreement that pharmacy-based vaccination could improve vaccination rates and result in cost savings, there was only moderate agreement that a pharmacy-based benefit would help improve public acceptance of vaccine safety and effectiveness. For those considering a pharmacy benefit, ease of access for patients and coordinated reporting of vaccine administration were most important. However, there was a lack of consensus when it came to the safety of vaccinations administered by pharmacists, due to the lack of pharmacists having access to a full patient history. When asked about the most useful type of information in evaluating a pharmacy-based vaccine benefit, models of best practice and vaccine registries were reported as most useful. Panelists disagreed regarding the utility of cost-effectiveness modeling, retrospective claims research, and patient surveys to evaluate pharmacy-based vaccination programs.

Responses to the postmeeting survey revealed that few attitudes had changed, possibly because most panelists had strong preformed opinions regarding adult vaccinations and the role of pharmacy-based benefits (see Table 1). For instance, postmeeting results indicated that panelists still disagreed about which factors would impact adult vaccination rates (i.e., vaccine cost and vaccine shortages) and who was most responsible for improving vaccination rates (i.e., government regulators and payers). However, postmeeting survey results did indicate consensus in some areas where panelists previously disagreed. For instance, premeeting results indicated panelists disagreed whether standardization of the payment process, uncertain cost-effectiveness, and safety concerns over pharmacists as vaccinators were barriers to a pharmacy-based benefit. According to postmeeting results, panelists agreed that uncertain costeffectiveness and the lack of a standardized payment process were barriers to a pharmacy-based benefit, but not safety of pharmacist-administered vaccinations. Other areas where consensus was achieved include the utility of cost-effectiveness modeling, retrospective claims analysis, and patient surveys, but all of these were considered only moderately useful.

Overall, results from the literature review, structured interviews, and premeeting survey identified 6 broad areas that provided direction for the expert panel meeting: benefit design, billing and payment, regulatory issues, immunization documentation and communication across providers, stakeholders who are responsible for adult vaccinations, and future research needs. Findings from the expert panel discussion are summarized as follows.

\section{Expert Panel}

This section highlights findings from the expert panel discussion, focusing on 6 key areas related to a pharmacy-based adult vaccine benefit.

Benefit Design. Panelists agreed that one of the most significant barriers to improving adult vaccination rates is benefit design in that members are simply not aware of the benefits available to them, benefits are confusing, and lack of understanding as to where benefits can be accessed. Thus, one of the first areas that should be addressed prior to implementing any benefit design change is to develop user-friendly tools to help members understand their benefits. The panelists believed that offering free vaccines is an insufficient incentive to increase vaccination rates and that members may need additional incentives (e.g., discounts on premiums) in addition to providing user-friendly tools to determine which benefits they have available and where they can access them. In addition to lack of awareness among members, the panelists stated that a lack of public recognition for the need for adult vaccinations is another important barrier impacting adult vaccination rates.

From an administrative standpoint, panelists reported that benefit design is strongly affected by third-party brokers of medical and pharmacy benefits. Brokers often purchase services in a piecemeal approach, with medical, pharmacy, and behavioral health benefits purchased separately. Panelists called for increased consistency specifically in the purchase of integrated services. It was also noted that purchasing an option for the integration of data among the various parts of the benefit is frequently overlooked or refused by the purchaser (i.e., employers). In this regard, there is a clear need for purchasers to keep brokers accountable in offering data integration and for buyers to include these services in the purchasing decision.

The panelists representing employers conveyed that outside of influenza, they were unaware of data suggesting any worker productivity benefits of increasing the rate of adult vaccinations or expanding such a benefit. These payers were not convinced of the cost-benefit of additional adult vaccines, particularly when balancing the additional cost of increased vaccination rates using alternative delivery methods such as pharmacy-based immunization. In this regard, it became clear that employers require strong value propositions before considering adding benefits or publicizing available/existing benefits.

Billing. Panelists agreed that the lack of coordinated payment processes between pharmacy and medical benefits and the 
administration of those benefits by the PBM and health plan are a significant barrier. Moreover, payment processes were also seen as one of the most important factors when considering the issues regarding offering a pharmacy-based vaccine benefit. A common issue mentioned by health plan and PBM panelists was duplicative billing. The case was made that physicians may be denied payment for a vaccine claim where the health plan had already reimbursed a pharmacy for administering the vaccine. Panelists indicated that coordination of services reporting among providers and the health plan/PBM is a priority. Coordinated reporting of vaccine administration beyond billing will be discussed separately.

Options for pharmacy billing of vaccination were also discussed, and the consensus opinion was that it would be most efficient to have pharmacies use the current National Council for Prescription Drug Programs (NCPDP) standard. Pharmacies already include the capability to bill for the product (i.e., vaccine) and administration of the vaccine separately, as opposed to introducing an alternative billing system based on the medical claim process. Rather than compel pharmacies to submit claims using the medical benefit billing system, the panel agreed that health plans and PBMs should accept billing for pharmacy administration of vaccines through the current NCPDP billing system. Additionally, no consensus was reached on how to approach restricted network capitation models where medical groups are responsible for providing all nondrug services, including vaccinations.

Regulatory/Scope of Practice. Although pharmacists are authorized to administer vaccines in every state, variations exist regarding the type of vaccines and age of eligible patients to which pharmacists can administer vaccines. Large employers with a presence in multiple states specifically mentioned varying state laws as a barrier in establishing a pharmacybased benefit, as large employers have to manage benefits differently across states. However, there was a lack of consensus within the panel as to whether or not varying state laws were in fact a barrier to a pharmacy-based benefit.

Among those who agreed state laws were a barrier to a pharmacy benefit, panelists mentioned that state medical association support would likely be required to expand state practice laws. In particular, state medical associations with the assistance of state/county public health associations and physician groups could help to support expanded state regulations authorizing pharmacists as full vaccine providers. The Patient Centered Primary Care Collaborative was suggested as a national organization that could fashion a policy statement to be utilized at the state level to support expanded practice authority for pharmacist vaccine administration.

Physician panelists reported that physicians are generally comfortable with pharmacists as vaccine providers, although the ability of pharmacists to properly screen patients for a wide range of vaccinations with limited patient history did raise some concern. Recent efforts with the H1N1 pandemic program were cited as a model of how loosening state law during a pandemic for pharmacists can be very effective at rapidly increasing vaccination rates. For example, pharmacistprovided immunizations expanded considerably following the $2009 \mathrm{H} 1 \mathrm{Nl}$ influenza pandemic and seasonal influenza outbreak. This public health crisis highlighted the role that pharmacists can play and positioned the profession to continue advancing immunization opportunities that improve public health by reaching patient populations in need or at risk. ${ }^{15,16}$

There was consensus that adult vaccination rates would also improve if patients had a pharmacy-based immunization benefit. Furthermore, health plan panelists indicated that physicians often carry a limited number of vaccines and that the provision of vaccinations may be a poor utilization of physician time. In fact, a recent study conducted by the American Medical Association found that only 20\%-30\% of internists and family physicians stocked all CDC-recommended vaccines; $80 \%$ were not planning on increasing their offerings; and $2 \%$ were planning to stop carrying vaccines altogether. ${ }^{17}$ There was continuing disagreement among panel members over provider status for pharmacists. Provider status for pharmacists under the Social Security Act is generally thought to be necessary to allow pharmacists to be consistently paid by Medicaid and private insurers. When asked to elaborate, those expressing hesitancy over pharmacists as vaccine providers indicated that without appropriate information exchange (i.e., communication back to the $\mathrm{PCP}$ ), physicians remain reluctant to recognize other providers as vaccinators. It appears that consensus is unlikely to be achieved regarding the recognition of pharmacists as vaccine providers until information exchange is more effectively coordinated between pharmacists and PCPs. It is important to note that the lack of information exchange encompasses not only pharmacists but others such as physician subspecialists, public health agencies, and hospitals.

One suggestion for establishing a closer link between pharmacists and PCPs was to include pharmacists into the primary care medical home model. ${ }^{18}$ Doing so could ensure that physicians are aware of any vaccinations that patients receive.

Immunization Documentation and Communication. There was broad agreement that lack of coordinated care between pharmacies and PCPs was a significant barrier related to pharmacy-based adult vaccinations. Current reporting practices include the pharmacy sending a fax or letter to the physician's office. However, this has not proven to be effective and, in many cases, is viewed as additional administrative work to get the information into the patient's record. Given the general absence of data sharing and reporting mechanisms, some health plans have retained vaccination benefits at the physician level rather than proactively building systems that coordinate 
the reporting of services among different providers. Despite the fact that panelists agree on the value of pharmacy as a high volume access point, the lack of data exchange between pharmacies and PCPs remains a significant barrier.

In order to address this issue, panelists suggested utilizing the electronic medical record (EMR) for 2-way communication between pharmacists and PCPs. One area where a collaborative approach was suggested is in the instance of a vaccination series, such as that for HPV or hepatitis B. It was suggested that the PCP could administer the first vaccination, with subsequent vaccinations taking place at a pharmacy. This could help alleviate the concern regarding the appropriateness of vaccination based on a patient's full medical history. Once the PCP transitions the responsibility for completing a vaccine series to the pharmacy/pharmacist, the issue of information exchange could also be addressed while also utilizing the increased accessibility of community pharmacists.

Panelists also suggested the inclusion of pharmacists in other electronic reporting solutions, such as immunization registries or state health information exchanges, as a way to increase coordinated care between pharmacists and PCPs. For example, providing pharmacists access to highly populated registries would allow pharmacists to actively seek, contribute, and view immunization records so that all providers are informed. Physicians currently can e-prescribe medications to pharmacies, and pharmacists can send refill requests back through the same system. Panelists suggested modifications to the current system by allowing pharmacists to update a physician's medical record using only their pharmacy information management system. Lastly, panelists reported that the expectation under new state health information exchanges (HIEs) is that every provider will have access to a real-time patient record, which could be used as a central vaccination record. However, in order for this to work, there is a need to have pharmacists recognized as providers within the HIEs. Establishing pharmacists as providers through state HIEs, coupled with access to patient records, may provide a reporting mechanism to PCPs and a basis for pharmacists to administer all vaccines. As with any reporting system, it is essential that providers check the system prior to providing services, something the panel indicated that neither physicians nor pharmacists currently do well, since they are better at data entry than retrieval.

Responsibility for Vaccination Rates. Panelists identified physicians as the most responsible for the improvement in adult vaccination rates, followed by patients, insurance companies, pharmacists, and employers. In addition, panelists focused on employers as having the potential to play a pivotal role in the improvement of adult vaccination rates. It was suggested that employers can specifically request that their health plans and brokers include a pharmacy-based vaccination benefit in their benefit design. For smaller employers, this may mean working closely with brokers to specify benefit design decisions to include a pharmacy-provided benefit, even if vaccinations remain part of the medical benefit. In addition, member awareness of available health benefits was also viewed as the responsibility of the employer, given that employers are most invested in the health of their employees. Employers are encouraged to work with the health plan/PBM to provide employees with easy-to-understand descriptions of their health benefits and how to access them.

There was also consensus that community pharmacies can play a more substantial role in increasing adult vaccination rates. Health plan representatives reported that one of their primary concerns was whether or not community pharmacies could provide consistent services across locations and be able to deliver vaccinations during all business hours. However, professional pharmacy associations report that pharmacists have already started addressing this issue, with more than 60,000 community pharmacies in the United States reportedly offering convenient, accessible, and extended hours of operation for vaccine administration. ${ }^{19,20}$

One suggestion was that pharmacists have an opportunity to make a larger contribution to help improve public health. If vaccination benefits were to be expanded to include pharmacy administration, the expectation was that pharmacists should leverage patient encounters to not only provide vaccines, but also take the opportunity to provide other preventive health services as recommended by the U.S. Preventative Health Services Task Force. There was concern that focused provision of vaccination alone may squander an opportunity to provide additional preventive health services such as counseling regarding additional ACIP-recommended vaccines, monitoring health status, and performing additional health screenings. Panelists recognized the potential value of the pharmacy-based patient encounter as an opportunity to provide other preventive health measures to complement the current physician-based system.

Health plan and PBM responsibilities regarding vaccinations were also addressed by the panel. The panel recognized that health plans and PBMs often operate independently and under different medical and pharmacy benefit silos. Regardless, the panel believed these entities were responsible for and best positioned to provide data integration across providers. In addition, health plans and PBMs should work with employers to improve the patient experience accessing and using their health benefits. While vaccine manufacturers were seen as just moderately responsible for improving adult vaccination rates, the panel strongly suggested that manufactures were responsible for the perception of vaccine efficacy, safety, and value by providing appropriate messaging with high-quality evidence.

Consensus was not achieved regarding the role of government regulators and government payers (e.g., Centers for Medicare \& Medicaid Services) and their responsibility in improving adult vaccination rates. Among those who felt the 
government had a limited role, it was suggested that government responsibilities for adult vaccinations were limited to public health agency recommendations.

Future Research. Employers called for additional research demonstrating the value of adult vaccines beyond seasonal flu. It was apparent that employers remained skeptical regarding the near-term value associated with increasing adult vaccination rates by offering adult vaccines through pharmacydelivered benefits or other providers. Employers are interested in additional information to help them determine the value of increasing adult vaccination rates and offering the additional benefit of pharmacy-based vaccinations.

Outcomes of particular interest to employers included employee productivity, absenteeism, and the overall cost-effectiveness of adult vaccines. Health plan panelists were interested in reduction of adverse events and the elimination of duplicative billing charges. Evidence of value needs to be specific for the various adult vaccines, as panelists generally agreed that influenza, tetanus diphtheria-pertussis (Tdap), and pneumococcal vaccines likely provide near-term value, but they were much less certain of the value provided by other vaccines such as herpes zoster and HPV.

Panelists perceived that employers had poor understanding of the low rate of adult vaccinations within their populations and where vaccinations were currently being administered. In this regard, providing data on vaccination and utilization rates may help highlight the importance of this issue and also help employers understand the importance of improving adult vaccination rates.

Health plan panelists also mentioned that Healthcare Effectiveness Data and Information Set (HEDIS) scores, Centers for Medicare \& Medicaid Services stars ratings, and accountable care organizations associated targets for adult vaccination rates provide an incentive to increase rates, potentially through expanded access. Focusing on adult vaccinations as part of quality measures would help all stakeholders recognize the importance of adult vaccines.

Panelists identified that the 2 most important sources of information when evaluating the impact of a pharmacy-based benefit were peer-review journals and ACIP recommendations. In addition, panelists indicated the organizations best suited to conduct future research would be academic institutions or independent research organizations.

\section{Workgroup Recommendations}

During the final session of the expert panel meeting, panelists were asked to provide specific actionable recommendations across the 6 topics discussed throughout the expert panel meeting. Specific workgroup recommendations outlining a roadmap to a pharmacy-based adult immunization benefit are presented in Table 2.

\section{Discussion}

The Patient Protection and Affordable Care Act (PPACA), signed into law in 2010, requires government and commercial plans to cover essential benefits, which include wellness and clinical preventive services, including vaccines recommended by the CDC's ACIP. These services must be offered without cost sharing by nongrandfathered health plans, and there are financial incentives for states to increase their coverage of preventive services.

Pharmacists and community pharmacy locations are in an ideal position to meet this growing need for preventative services. Pharmacist-provided immunizations are clinically sound, cost effective, readily accessible, and have demonstrated the ability to support our nation's public health goals. Although there are varying state regulations regarding pharmacists as vaccine administrators, all 50 states currently allow pharmacists to administer vaccines. ${ }^{17,21,22}$ Duncan et al. (2012) created a cost-benefit model around influenza vaccination programs and reported that an influenza immunization program is cost beneficial to employers when more than $37 \%$ of individuals receive vaccine in nontraditional settings such as pharmacies, with an estimated net saving of $\$ 6$ per vaccine. ${ }^{23}$ In addition, Prosser et al. (2008) reported that the cost (2004 U.S. dollars) of vaccination was lower in mass vaccination clinics (\$17.04) and pharmacy (\$11.57) settings than in scheduled doctor's office visits $(\$ 28.67) .^{24}$

The purpose of this project was to identify issues and barriers related to a pharmacy-based adult vaccine benefit and develop recommendations to support a pathway for benefit design change. Based on our findings, the barriers associated with overcoming a pharmacy-based benefit revolve around 3 distinct areas: increased engagement by employers, lack of coordinated reporting, and insufficient recognition of the community pharmacy and pharmacist as vaccine providers.

First, it is clear that employers must play a more proactive role in incorporating explicit changes in benefit design. However, in order to consider any benefit changes, they require sound value propositions to guide directed use of limited organizational resources. As such, pharmacy vaccination benefit would have to show relatively greater near-term value in comparison to other health management initiatives to prompt sufficient employer focus to enhance vaccine benefit design. Although employers are not necessarily calling for costeffectiveness data given the relatively low cost of vaccines, they would benefit from more substantial evidence demonstrating the impact of adult vaccines on health care costs and workforce productivity and absenteeism.

Second, from an administrative standpoint, the ability to ensure consistent reporting and data exchange between community pharmacists and PCPs is of significant importance. Due to issues such as the potential for duplicative billing and lack of data exchange between pharmacies and PCPs, 


\begin{tabular}{|c|c|}
\hline & Recommendations \\
\hline Benefit design & $\begin{array}{l}\text { - Increase member awareness of what benefits are covered and how to access them with user-friendly applications } \\
\text { - Health care brokers and purchasers (i.e., employers) need to offer and purchase or develop data integration services across medical and } \\
\text { pharmacy benefits } \\
\text { - Provide evidence to support value propositions for employers demonstrating near-term value of increasing access to a broad range of } \\
\text { adult vaccines } \\
\text { - Create pharmacy-based vaccine benefits that use one of the following models: } \\
\text { o Include vaccines and vaccine administration on a PBM's list of covered products } \\
\text { o Bring pharmacies into a health plan's medical network to allow in-network delivery of the vaccine as a medical benefit }\end{array}$ \\
\hline Billing & $\begin{array}{l}\text { - All vaccine providers need to have easily accessible data regarding services provided by other health care providers to avoid duplicate } \\
\text { billing issues } \\
\text { - Utilize current pharmacy information management systems for processing adult vaccination claims and have the health plan or PBM } \\
\text { attach the claim to the appropriate benefit }\end{array}$ \\
\hline Regulatory & $\begin{array}{l}\text { - Develop a nationally endorsed policy statement to be used by state medical associations and state/county health departments support- } \\
\text { ing pharmacists as vaccine providers } \\
\text { - Conduct a "proof of concept" project in select states generating real-world data demonstrating successful information exchange between } \\
\text { pharmacies and health plans }\end{array}$ \\
\hline $\begin{array}{l}\text { Immunization } \\
\text { documentation } \\
\text { and } \\
\text { communication }\end{array}$ & $\begin{array}{l}\text { - Provide a method for real-time reporting of vaccines administered among all types of providers and the health plan/PBM } \\
\text { - Develop protocols for the administration of a vaccination series, which includes coordination among physicians and pharmacists using } \\
\text { the EMR where available } \\
\text { - Include pharmacists as providers within state HIEs }\end{array}$ \\
\hline $\begin{array}{l}\text { Responsibility } \\
\text { for vaccination } \\
\text { rates }\end{array}$ & $\begin{array}{l}\text { - Employers need to be more proactive in promoting member awareness of health care benefits, including the value of vaccines and } \\
\text { where to access them } \\
\text { - Ensure that community pharmacies have trained pharmacists and protocols to deliver vaccinations consistently across all facilities and } \\
\text { during all business hours } \\
\text { - Pharmacists should use the vaccine encounter to provide more comprehensive preventive health services } \\
\text { - Manufacturers need to provide additional evidence and effective messaging regarding the efficacy, safety, and value of vaccines to help } \\
\text { improve public and payer perception of adult vaccinations }\end{array}$ \\
\hline Future research & $\begin{array}{l}\text { - Generate additional evidence on the cost benefit of adult vaccinations, focusing on productivity and absenteeism } \\
\text { - Include adult vaccination rates for ACIP-recommended vaccines as quality measures within the National Committee for Quality } \\
\text { Assurance HEDIS quality reporting dataset } \\
\text { - Partner with independent academic institutions or third-party research organizations to conduct additional studies }\end{array}$ \\
\hline
\end{tabular}

competition for patients, and potential revenue loss, there is reluctance among physicians and health plans to recognize pharmacists as vaccine providers. However, this does not call for an entirely new billing system; instead, the preference is to leverage the NCPDP pharmacy claims transmission standard that is already in place. Furthermore, the timing of a pharmacy benefit is ideal, given the PPACA and state HIEs that are being established, which also have the potential to address concerns around information exchange. The millions of newly insured individuals, along with those now entitled to no-cost vaccines, provide justification to expand the pool of available sources and providers for adult vaccinations. Pharmacists are poised to fill that need, and technology to enhance immunization documentation communication is improving.

Third, despite the fact that physicians are generally accepting of pharmacists as vaccine providers, pharmacists have an opportunity and obligation to serve a broader role. If pharmacists are to be recognized as providers, they must take advantage of the patient encounter and provide other preventive health care measures, such as medication adherence. To ensure that pharmacists have the ability to do so, endorsement from external groups such as medical professional associations and state and local/county public health organizations would help pharmacists be recognized as providers from a preventive health perspective, not only of vaccinations but of helping to establish their role as important members of the health care team. Nationally, establishing pharmacists as providers under the Social Security Act will enable health plans and other providers to appropriately recognize pharmacists for participation in billing and data exchange.

Lastly, despite PPACA legislation and first-dollar coverage for adult vaccinations, utilization rates remain low. ${ }^{25}$ There is a compelling need for enhanced awareness of the value of adult vaccinations. All stakeholders in the health care delivery system can advocate for improved immunization rates by promoting available vaccination sources, including pharmacies. Additionally, employers can enhance communication efforts regarding adult preventive care services, including vaccines, with consideration for financial or other incentives to improve participation rates. 


\section{Limitations}

There are several limitations to be noted. First, due to the scope of the project, a convenience sample of 12 participants were included in the expert panel, and workgroup recommendations may not be representative of other organizations or states. For example, we only included employer representatives from large corporations, and panelists clearly indicated that benefit design decisions are likely to vary based on size of the employer, since large employers may have more flexibility in benefit design decisions. Second, our literature review was comprehensive in nature but may not have included all of the relevant topics to a pharmacy-based benefit. As a result, our study focused on 6 broad topics, but other factors are likely to be important when considering the merits of pharmacy-based vaccination. Panelists clearly indicated vaccines were viewed differently in terms of their efficacy, cost-effectiveness, and safety, making it difficult to generalize our findings across all adult vaccinations.

\section{Conclusions}

Consideration for a future state of pharmacy-based adult vaccinations comes at no better time, given the cultural shift taking place from an acute care model of health care towards a more preventive approach. As part of a team-based care delivery model that extends beyond the physical walls of the PCP office, community pharmacists are ideally trained and positioned to fill that role. Pharmacy-based access to vaccinations improves patient access and can benefit individuals and employers through reduction of the incidence of vaccine-preventable disease. In order to take advantage of this opportunity, pharmacists as providers must be viewed within the broader context of preventative health care, which includes pharmacy-based adult vaccinations.

\section{Authors}

KELLY J. KO, PhD, is Research Scientist; HSING-TING YU, $M P H$, is Principle Investigator; and ROSS M. MILLER, MD, $\mathrm{MPH}$, is Medical Executive, Cerner Corporation, Culver City, California. ROLIN L. WADE, RPh, MS, is a Principle, IMS Health, Parsippany, New Jersey; BRUCE SHERMAN, MD, is Medical Director, Employers Health Coalition, Inc., Canton, Ohio, and Assistant Clinical Professor, Case Western Reserve University School of Medicine, Cleveland, Ohio; and JEFF GOAD, PharmD, MPH, is Associate Professor, University of Southern California School of Pharmacy, Los Angeles, California.

AUTHOR CORRESPONDENCE: Kelly J. Ko, PhD, Cerner Research, 600 Corporate Pointe, Ste. 320, Culver City, CA 90230. Tel.: 310.598.4532; Fax: 816.936.9266; E-mail: Kelly.Ko@Cerner.com.

\section{DISCLOSURES}

This study was funded by Merck, Inc. No representatives from Merck attended the expert panel meeting, and they were blinded to the individuals chosen for the project. Ko, Yu, and Miller are employed by Cerner Research, which provides consulting services to the pharmaceutical industry. Goad provided consulting services to Cerner Research. Wade was employed by Cerner Research during the time of the study.

Study concept and design were contributed by Ko and Wade, with assistance from Yu. Ko, Wade, and Yu had primary responsibility for data collection, with assistance from Goad; data interpretation was primarily the work of Ko, Sherman, and Goad, with assistance from Wade. Ko was primarily responsible for writing the manuscript, with assistance from Sherman, Goad, and Wade; revision was primarily made by Ko, with assistance from Wade, Yu, Miller, Sherman, and Goad.

\section{ACKNOWLEDGMENTS}

The authors would like to thank the panelists for their participation in the expert panel meeting:

Eric Cannon, PharmD

SelectHealth

Salt Lake City, UT

Ed Cohen, PharmD, FAPhA

Walgreens

Deerfield, IL

John Fox, MD

Priority Health

Grand Rapids, MI

Douglas Hillblom, PharmD

California Pharmacy Association

Sacramento, CA

Maria Lopes, MD, MS

AMC Health

Cresskill, NJ

Ross M. Miller, MD, MPH

Cerner Corporation

Los Angeles, CA

One pharmacy director from a national health plan chose to remain anonymous.

We also gratefully acknowledge the very important contributions of Dr. Thomas Weiss, DrPH, to the design of this project. Weiss is a full-time employee of Merck, Inc.

\section{REFERENCES}

1. Centers for Disease Control and Prevention. National, state, and local area vaccination coverage among children aged 19-35 months-United States, 2011. MMWR Morb Mortal Wkly Rep. 2012;61:689-96. Available at: http://www.cdc.gov/mmwr/preview/mmwrhtml/mm6135al.htm?s_ cid=mm6135al_e\%0d\%0a. Accessed December 9, 2013.

2. Centers for Disease Control and Prevention. Noninfluenza vaccination coverage among adults-United States, 2011. MMWR Morb Mortal Wkly Rep. 2013;62(4):66-72. Available at: http://www.cdc.gov/mmwr/preview/mmwrht$\mathrm{ml} / \mathrm{mm} 6204 a 2 . h t m$ ?s_cid=mm6204a2_w. Accessed December 9, 2013.

3. Centers for Disease Control and Prevention. Statistics and surveillance: 2011 NIS-teen vaccination coverage table data. August 30, 2012. Available at: http://www.cdc.gov/vaccines/stats-surv/nisteen/data/tables_2011.htm. Accessed December 9, 2013.

4. Orenstein WA, Douglas RG, Rodewald LE, Hinman AR. Immunizations in the United States: success, structure, and stress. Health Aff (Millwood). 2005;24(3):599-610.

5. Shen AK. The U.S. vaccine and immunization enterprise: Working to sustain and foster vaccine innovation. Hum Vaccin. 2009;5(10):649-53. 
6. Johnson DR, Nichol KL, Lipczynski K. Barriers to adult immunization. Am J Med. 2008;121(7 Suppl 2):S28-S35.

7. National Vaccine Advisory Committee. Adult immunization: complex challenges and recommendations for improvement. February 25, 2011. Available at: http://www.hhs.gov/nvpo/nvac/subgroups/wg_report_ v2_25feb2011.pdf. Accessed December 9, 2013.

8. Madjid M, Alfred A, Sahai A, Conyers JL, Casscells SW. Factors contributing to suboptimal vaccination against influenza: results of a nationwide telephone survey of persons with cardiovascular disease. Tex Heart Inst J. 2009;36(6):546-52.

9. Committee on the Evaluation of Vaccine Purchase Financing in the United States. Financing Vaccines in the 21st Century: Assuring Access and Availability. Washington, DC: National Academies Press; 2013. Available at: http://www.nap.edu/openbook.php?record_id=10782\&page=1. Accessed December 9, 2013.

10. Trust for America's Health. Adult immunization: shots to save lives. February 2010. Available at http://healthyamericans.org/assets/files/ TFAH2010AdultImmnzBrief13.pdf. Accessed December 9, 2013.

11. National Vaccine Advisory Committee. Recommendations for federal adult immunization programs regarding immunization delivery, assessment, research, and safety monitoring. June 2, 2009. Available at: http://www.hhs. gov/nvpo/nvac/subgroups/nvacadultimmunizationsworkinggroupjune2009. html. Accessed December 9, 2013.

12. Shen AK, Sobzcyk E, Buchanan A, Wu L, Duggan-Goldstein S. Second National Immunization Congress 2010: addressing vaccine financing for the future in the U.S. Hum Vaccin. 2011;7(1):12-18.

13. Skelton JB. Pharmacist-provided immunization compensation and recognition: white paper summarizing APhA/AMCP stakeholder meeting. J Am Pharm Assoc (2003). 2011;51(6):704-12.

14. Jones J, Hunter D. Consensus methods for medical and health services research. BMJ. 1995;311(7001):376-80.

15. Poland GA. The 2009-2010 influenza pandemic: effects on pandemic and seasonal vaccine uptake and lessons learned for seasonal vaccination campaigns. Vaccine. 2010;28(Suppl 4):D3-13.
16. Rambhia KJ, Watson M, Sell TK, Waldhorn R, Toner E. Mass vaccination for the $2009 \mathrm{H} 1 \mathrm{Nl}$ pandemic: approaches, challenges, and recommendations. Biosecur Bioterror. 2010;8(4):321-30.

17. American Pharmacists Association. Pharmacist administered vaccines: types of vaccines authorized to administer. May 2012. Available at: http:// www.pharmacist.com/sites/default/files/files/PharmacistIZAuthority_ May2012.pdf. Accessed December 9, 2013.

18. Agency for Healthcare Research and Quality. Patient centered medical home resource center. 2013. Available at: http://www.pcmh.ahrq.gov/portal/ server.pt/community/pcmh__home/1483. Accessed December 9, 2013.

19. National Association of Chain Drug Stores. Industry. 2013 Available at: http://www.nacds.org/aboutus/industry.aspx. Accessed December 9, 2013.

20. National Community Pharmacists Association. NCPA Digest finds independent community pharmacies stable despite economic, third-party challenges. October 25, 2010. Available at: www.ncpanet.org/index.php/ news-releases/787-ncpa-digest-finds-independentcommunity-pharmaciesstable-despite-economic-third-partychallenges. Accessed December 9, 2013.

21. Carpenter L. Pharmacist-administered immunizations: trends in state laws. Drug Store News. September 2009. Available at: http://www.cedrugstorenews.com/userapp//lessons/page_view_ui.cfm?lessonuid=\&pageid=B92 3321F24938AEE0854C1225838355F. Accessed December 9, 2013.

22. Madhavan SS, Rosenbluth SA, Amonkar M, Borker RD, Richards T. Pharmacists and immunizations: a national survey. J Am Pharm Assoc (Wash). 2001;41(1):32-45.

23. Duncan IG, Taitel MS, Zhang J, Kirkham HS. Planning influenza vaccination programs: a cost benefit model. Cost Eff Resour Alloc. 2012;10(1):10.

24. Prosser LA, O'Brien MA, Molinari NA, et al. Non-traditional settings for influenza vaccination of adults: costs and cost effectiveness. Pharmacoeconomics. 2008;26(2):163-78.

25. U.S Department of Health and Human Services. Immunizations and infectious diseases. Healthy People 2020. November 13, 2013. Available at: http://www.healthypeople.gov/2020/topicsobjectives2020/overview. aspx?topicid=23. Accessed December 9, 2013. 


\section{APPENDIX A Structured Interview Guide}

Adult Immunization Background

1. Tell me about your adult vaccine benefit [HEALTH PLAN RESPONDENTS]

a. What adult vaccines are covered and under what type of benefit? Any restrictions on particular adult vaccines?

i. Flu, pneumovax, H Zoster, Td, Tdap, Hep A, Hep B, MMR, meningitis, others

b. Are your adult vaccines covered under a pharmacy benefit or via alternate benefit arrangements, or only under a medical benefit?

What adult vaccines are you aware of that are covered by health insurance? [NON-HEALTH PLAN RESPONDENTS]

2. What do you believe are the most important challenges in the area of adult immunizations?

a. What are your goals for adult immunization?

b. Are you satisfied with (your) uptake and completion rates for adult vaccinations?

c. Have you implemented (are you familiar with) any strategies to try and improve vaccination rates in your adult population?

i. Were (do you believe) these improvement strategies (are) successful? Why or why not?

d. Are there particular vaccines that are more difficult than others to increase immunization rates? (i.e., flu, shingles, hepatitis)?

e. How could the benefit design affect (your) adult immunization goals?

Pharmacy-Based Adult Vaccines \& Barriers

3. Have you considered (or implemented) a pharmacy-based adult vaccine benefit, or have you discussed this with your health plan?

[HEALTH PLAN RESPONDENTS]

a. Why or why not, what is (or would be) the motivation?

b. What are (were) the barriers (or perceived barriers)?

c. If yes - what were the barriers you had to overcome?

i. $\quad$ Are there ongoing challenges?

ii. If your health plan already offers a pharmacy-based immunization benefit, how effective has it been in terms of uptake/completion rates, cost savings, etc?

d. If no, what would increase your interest in (developing) a pharmacy-based vaccination benefit?

i. What do you believe has to take place in order to provide pharmacy-based immunization benefits? (In your plan or health plans in general)

4. What do you believe are the most significant barriers related to implementing a pharmacy-based adult immunizations benefit?

[ 1 = insignificant, 5 = neutral, 9 = significant $]$

a. Administrative/reimbursement/network logistics

b. Cost-benefit ratio (i.e., increased cost due to more vaccine providers and more people getting vaccinated)

c. Actuarial-PMPM cost estimate

d. No unmet need for adult vaccination/no demand

e. Offers no competitive advantage

f. Varying state laws on pharmacy regulations (i.e., licensing requirements)

g. Inconsistent availability within pharmacy network

h. Documentation of vaccination/record keeping/quality measurement

i. Abrasion of the medical network

j. Anything else? [ADDITIONAL EXAMPLES BELOW]

i. Fragmentation of immunization delivery, lack of reporting to the insurer and PCP, over-vaccination due to different levels of insurance verification (real-time vs. retrospective), skill level of pharmacist, capitated vs. PPO/FFS, Restricted Networks (under ACA).

5. Have you addressed any of the barriers identified above?

a. What approach(es) did you take?

b. Were they resolved, unresolved?

c. What do you believe will have to change to overcome these hurdle(s)?

6. How important to you are (were) the following considerations in implementing a pharmacy-based adult immunization benefit? [ $1=$ not important, $5=$ neutral, 9 = very important $]$ - OPTIONAL

a. Ease of access for patients?

b. Member satisfaction

c. Lack of availability of (all) vaccines routinely from medical providers?

d. Cost? (medical vs. pharmacy)

e. Cost effectiveness vs. cost benefit

i. What specific data would be useful?

ii. What are the most important measures?

iii. What inputs and outputs would you want to see? 


\section{APPENDIX A Structured Interview Guide (continued)}

f. Reimbursement

g. Logistics of reimbursement through the pharmacy payment systems

h. PBM vs. medical benefit

i. Physician perception of a pharmacy-based immunization benefit

j. Other factors?

Future Studies/Resources

7. What kind of data/studies would be most useful to your health plan when (if) considering an adult vaccine pharmacy-benefit? [HEALTH PLAN RESPONDENTS]

What kind of data/studies do you believe would be most useful for health plans considering an adult vaccine pharmacy-benefit? [NON-HEALTH PLAN RESPONDENTS]

a. Who would be the most appropriate organization to produce such data, inappropriate?

b. What would you consider to be important or convincing results? i. Specifically, in what areas would you need to see changes?

c. Are you aware of any data supporting the value of pharmacy-based programs? If so, what was your impression of that data?

8. Where do you go for tools and advice regarding a pharmacy-based adult vaccination benefit?

a. What guidelines or professional organizations do you most refer to when considering benefit design change in the area of immunization?

9. Would you want a credentialed network of pharmacists who provide your vaccinations? [HEALTH PLAN RESPONDENTS]

a. If so, what would you want to know about them? (e.g., training, DEA/DOJ/CMS background, license in good standing, etc.)

ACA =Affordable Care Act; CMS = Centers for Medicare \& Medicaid Services; DEA = Drug Enforcement Administration; DOJ=Department of Justice; FFS =fee-for-service; $P B M=$ pharmacy benefit manager; $P C P=$ primary care provider; $P M P M=$ per member per month; $P P O=$ preferred provider organization. 


\section{APPENDIX B Premeeting Survey}

Section I: Background

1. How strongly do you agree or disagree that the following factors impact adult vaccination rates?

1 = Strongly disagree, 5 = Neutral, $9=$ Strongly agree

a. Health plan benefit design strongly influences adult vaccination rates (i.e., uptake/completion)

b. Scope of practice issues limiting the availability of vaccinations at different locations (i.e., physician office, clinic, pharmacies)

c. Lack of public recognition of the need for adult vaccination

d. Public perception that vaccine risk does not outweigh benefits

e. Cost of vaccines (for patients)

f. Vaccine shortages

g. Other, please describe:

2. How much responsibility do the following stakeholders have in helping to improve adult vaccination rates?

$1=$ No responsibility, $5=$ Neutral, $9=$ Very high responsibility

a. Patients

b. Physicians

c. Pharmacists

d. Employers

e. Insurance companies/health plans/PBMs

f. Vaccine manufacturers/suppliers

g. Centers for Disease Control (CDC)/Advisory Committee on Immunization Practices (ACIP)

h. Government regulators

i. Government payers (e.g., Centers for Medicare \& Medicaid Services)

j. Public health agencies (state, county)

k. Professional societies, if so which ones:

1. Other, please describe:

3. What do you believe is the most significant barrier/challenge to improving adult vaccination rates?

Section II: Pharmacy-based adult vaccination benefit

4. Does your organization currently offer a pharmacy-based adult vaccine benefit? [HEALTH PLAN PANELISTS]

Are you directly involved with any adult-based vaccination programs? [NON-HEALTH PLAN PANELISTS]

a. Yes, if so please describe and for how long?

b. No, if not what would increase your interest?

5. How strongly do you agree/disagree that pharmacy-based adult vaccination benefit availability would help improve the following: $1=$ Strongly disagree, $5=$ Neutral, $9=$ Strongly agree

a. Adult vaccination rates (i.e., uptake/completion rates)

b. Cost savings (for the health insurer and/or employer)

c. Public acceptance of vaccine safety and effectiveness

6. How strongly do you agree/disagree that the following are barriers/challenges related to a pharmacy-based adult vaccine benefit? 1 = Strongly disagree, $5=$ Neutral, $9=$ Strongly agree

a. Mechanisms to process reimbursements between the pharmacy and health plan or PBM

b. Coordination of reporting of vaccination to primary care providers

c. Uncertain cost-effectiveness

d. Increased net cost to payer (i.e., increased number of claims for vaccinations)

e. Varying state laws on pharmacy regulations (i.e., pharmacy practice acts)

f. Complexity of establishing and credentialing a pharmacy network

g. Recognition of the pharmacist as a vaccine provider

h. Perception by physicians that pharmacists are taking their revenue/patients

i. Concern that pharmacists do not obtain adequate patient history to safely administer all adult vaccines

j. Other, please describe:

7. How important to your decision making are the following factors when considering a pharmacy-based adult vaccine benefit?

1 = Unimportant, $5=$ Neutral, 9 = Very important

a. Ease of access to vaccinations for my members/employees

b. Member/employee satisfaction or loyalty to the health plan/company 


\section{APPENDIX B Premeeting Survey (continued)}

c. Availability of a wide range of adult vaccines

d. Reimbursement processes

e. Coordinated and consistent reporting of vaccines administered

f. Other, please describe:

8. What do you believe are the two (2) most significant challenges (to your health plan or to other stakeholders) in establishing a pharmacy-based adult vaccination benefit?

\section{Section III: Future studies/resources}

9. What kind of data/study types do you believe are most useful when evaluating a pharmacy-based adult vaccination benefit?

$1=$ Not at all useful, $5=$ Neutral, $9=$ Very useful

a. Cost-effectiveness modeling

b. Prospective studies

c. Retrospective administrative claims analyses

d. Models of best practices

e. Registry data

f. Patient surveys

g. Provider surveys

h. Other, please describe

10. What are the most useful/important sources of information when evaluating a pharmacy-based adult vaccine benefit?

$1=$ Not useful/unimportant, $5=$ Neutral, $9=$ Very useful/important

a. Morbidity and Mortality Weekly Report (MMWR)

b. ACIP recommendations

c. Peer-reviewed journal articles

d. Professional association guidelines

e. Professional conferences/meetings

f. Newsletters

g. Internet, please indicate websites:

h. Discussion with colleagues

i. Other, please describe:

11. What public and/or private organizations are best suited or the most credible to conduct studies or disseminate information about pharmacy-based adult vaccination benefits? 


\section{APPENDIX C Supplemental Data}

How strongly do you agree or disagree that the following factors impact adult vaccination rates (i.e., uptake/completion)?

\begin{tabular}{|c|c|c|c|c|c|c|c|c|}
\hline & \multicolumn{2}{|c|}{ Disagreement (1-3) } & \multicolumn{2}{|c|}{ Unsure (5-7) } & \multicolumn{2}{|c|}{ Agreement (7-9) } & \multicolumn{2}{|c|}{ Mean } \\
\hline & Pre $^{\mathrm{a}}$ & Post $^{\mathrm{a}}$ & Pre & Post & Pre & Post & Pre & Post \\
\hline Health plan benefit design & 1 & 2 & 2 & 2 & 9 & 8 & 7.08 & 6.58 \\
\hline Scope of practice issues & 1 & 0 & 2 & 2 & 9 & 10 & 7.08 & 7.42 \\
\hline Lack of public recognition & 1 & 0 & 2 & 1 & 9 & 11 & 7.25 & 7.83 \\
\hline Public perception that vaccine risk > benefits & 0 & 1 & 5 & 3 & 7 & 8 & 6.75 & 6.50 \\
\hline Cost of vaccines for patients & 2 & 3 & 6 & 5 & 3 & 4 & 5.75 & 5.25 \\
\hline Vaccine shortages & 4 & 4 & 2 & 4 & 6 & 4 & 5.33 & 5.42 \\
\hline
\end{tabular}

How much responsibility do the following stakeholders have in helping to improve adult vaccination rates?

\begin{tabular}{|c|c|c|c|c|c|c|c|c|}
\hline & \multicolumn{2}{|c|}{ Disagreement (1-3) } & \multicolumn{2}{|c|}{ Unsure (5-7) } & \multicolumn{2}{|c|}{ Agreement (7-9) } & \multicolumn{2}{|c|}{ Mean } \\
\hline & Pre $^{\mathrm{a}}$ & Post $^{\mathrm{a}}$ & Pre & Post & Pre & Post & Pre & Post \\
\hline Patients & 0 & 1 & 1 & 0 & 11 & 11 & 7.92 & 7.67 \\
\hline Physicians & 0 & 0 & 0 & 0 & 12 & 12 & 8.33 & 8.58 \\
\hline Pharmacists & 1 & 0 & 2 & 4 & 9 & 8 & 7.00 & 7.25 \\
\hline Employers & 0 & 0 & 4 & 3 & 8 & 9 & 7.08 & 7.17 \\
\hline Insurance companies/health plans/PBMs & 1 & 0 & 0 & 3 & 11 & 9 & 7.50 & 7.42 \\
\hline Vaccine manufacturers/suppliers & 0 & 1 & 4 & 6 & 8 & 5 & 6.75 & 5.92 \\
\hline CDC/ACIP & 1 & 1 & 2 & 3 & 9 & 8 & 7.17 & 7.08 \\
\hline Government regulators & 2 & 3 & 5 & 3 & 5 & 6 & 5.50 & 5.50 \\
\hline Government payers (e.g. CMS) & 2 & 2 & 0 & 3 & 10 & 7 & 6.58 & 6.00 \\
\hline Public health agencies (state, county) & 1 & 1 & 1 & 2 & 10 & 7 & 7.08 & 6.92 \\
\hline Professional societies & 1 & 1 & 5 & 5 & 6 & 6 & 6.33 & 6.25 \\
\hline
\end{tabular}

How strongly do you agree/disagree the availability of a pharmacy-based adult vaccination benefit would help improve the following:

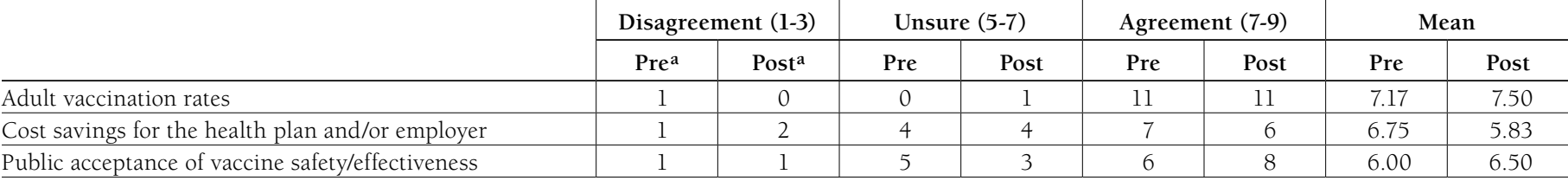

How strongly do you agree/disagree that the following are barriers/challenges related to a pharmacy-based adult vaccine benefit?

\begin{tabular}{|c|c|c|c|c|c|c|c|c|}
\hline & \multicolumn{2}{|c|}{ Disagreement (1-3) } & \multicolumn{2}{|c|}{ Unsure (5-7) } & \multicolumn{2}{|c|}{ Agreement (7-9) } & \multicolumn{2}{|c|}{ Mean } \\
\hline & Pre $^{\mathrm{a}}$ & Post $^{\mathrm{a}}$ & Pre & Post & Pre & Post & Pre & Post \\
\hline Lack of standardized reimbursement process & 2 & 0 & 1 & 2 & 9 & 10 & 6.92 & 7.75 \\
\hline Coordinated reporting of vaccination to PCP & 1 & 2 & 3 & 0 & 8 & 10 & 6.75 & 7.08 \\
\hline Uncertain cost-effectiveness & 4 & 1 & 5 & 7 & 3 & 4 & 5.08 & 5.67 \\
\hline Increased net cost to payer (i.e., increase in claims) & 4 & 3 & 7 & 7 & 1 & 2 & 4.33 & 5.00 \\
\hline$\underline{\text { Varying state laws on pharmacy regulations }}$ & 2 & 2 & 6 & 3 & 4 & 7 & 6.08 & 6.17 \\
\hline Complexity of establishing a pharmacy network & 2 & 5 & 8 & 5 & 2 & 2 & 5.08 & 4.33 \\
\hline Recognition of the pharmacist as a vaccine provider & 2 & 3 & 6 & 5 & 4 & 4 & 5.75 & 5.67 \\
\hline Perception that pharmacists are taking revenue & 4 & 3 & 4 & 7 & 4 & 2 & 5.08 & 4.92 \\
\hline Pharmacists ability to safely administer vaccines & 5 & 7 & 4 & 4 & 3 & 1 & 4.75 & 3.25 \\
\hline
\end{tabular}

How important to your decision making are the following factors when (if) considering a pharmacy-based adult vaccine benefit?

\begin{tabular}{|c|c|c|c|c|c|c|c|c|}
\hline & \multicolumn{2}{|c|}{ Disagreement (1-3) } & \multicolumn{2}{|c|}{ Unsure (5-7) } & \multicolumn{2}{|c|}{ Agreement (7-9) } & \multicolumn{2}{|c|}{ Mean } \\
\hline & Pre $^{a}$ & Post $^{\mathrm{a}}$ & Pre & Post & Pre & Post & Pre & Post \\
\hline Ease of access to vaccinations for members/employees & 1 & 1 & 1 & 1 & 10 & 10 & 7.42 & 7.75 \\
\hline Member/employee satisfaction & 1 & 1 & 4 & 4 & 7 & 7 & 6.58 & 6.58 \\
\hline Availability of a wide range of adult vaccines & 1 & 1 & 6 & 7 & 5 & 4 & 6.17 & 6.00 \\
\hline Reimbursement processes & 1 & 0 & 3 & 0 & 8 & 12 & 6.83 & 7.67 \\
\hline Coordinated and consistent reporting & 0 & 0 & 3 & 0 & 9 & 12 & 7.25 & 8.33 \\
\hline
\end{tabular}




\section{APPENDIX C Supplemental Data (continued)}

What kind of data/study TYPES do you believe are most useful when evaluating a pharmacy-based adult vaccination benefit?

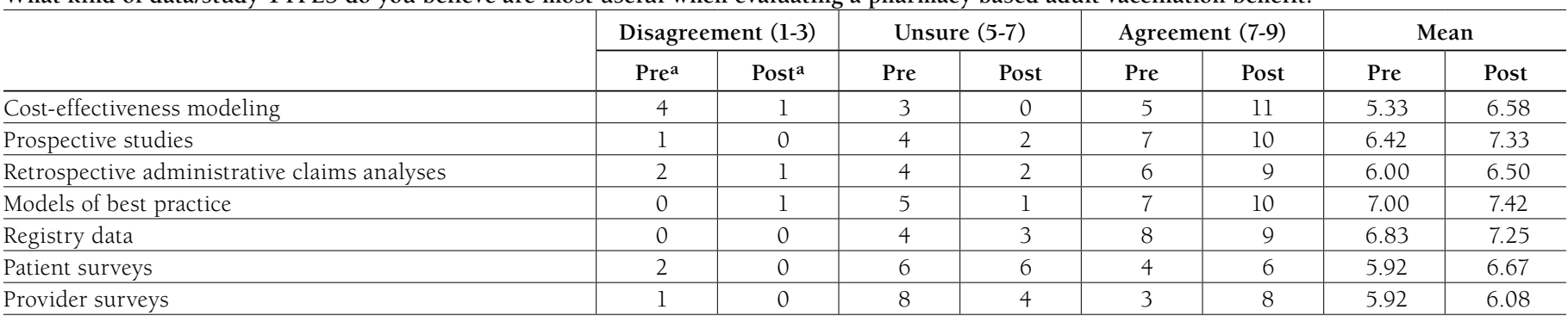

What are the most useful/important SOURCES of information when evaluating a pharmacy-based adult vaccine benefit?

\begin{tabular}{|c|c|c|c|c|c|c|c|c|}
\hline & \multicolumn{2}{|c|}{ Disagreement (1-3) } & \multicolumn{2}{|c|}{ Unsure (5-7) } & \multicolumn{2}{|c|}{ Agreement (7-9) } & \multicolumn{2}{|c|}{ Mean } \\
\hline & Pre $^{a}$ & Post $^{\mathrm{a}}$ & Pre & Post & Pre & Post & Pre & Post \\
\hline Morbidity and Mortality Weekly Report (MMWR) & 2 & 0 & 4 & 4 & 6 & 8 & 6.00 & 6.92 \\
\hline ACIP recommendations & 0 & 0 & 2 & 3 & 10 & 9 & 7.67 & 7.50 \\
\hline Peer-reviewed journal articles & 0 & 0 & 5 & 1 & 7 & 11 & 6.92 & 7.92 \\
\hline Professional association guidelines & 0 & 1 & 8 & 3 & 4 & 8 & 5.92 & 6.58 \\
\hline Professional conference/meetings & 3 & 1 & 6 & 4 & 3 & 7 & 5.25 & 6.17 \\
\hline Newsletters & 4 & 3 & 5 & 6 & 3 & 3 & 4.50 & 5.00 \\
\hline Discussion with colleagues & 3 & 1 & 6 & 5 & 3 & 6 & 5.33 & 6.00 \\
\hline Internet & 2 & 3 & 8 & 5 & 2 & 4 & 4.83 & 5.17 \\
\hline
\end{tabular}

a Denotes number of panelists who were in disagreement, unsure, or agreement with respective survey questions.

$A C I P=$ Advisory Committee on Immunization Practice; $C D C=$ Centers for Disease Control and Prevention; $C M S=$ Centers for Medicare $\&$ Medicaid Services;

$P B M=$ pharmacy benefit manager; $P C P=$ primary care provider . 